\title{
Aspectos históricos relacionados à adoção de práticas agroecológicas: análise retrospectiva no Oestemaranhense
}

\section{Historical aspects related to the adoption of agroecological practices. Retrospective analysis in Western Maranhão}

\begin{abstract}
Xoán Carlos Sánchez Couto - Mestre em Agriculturas Familiares e Desenvolvimento Sustentável pela Universidade Federal do Pará. Engenheiro agrônomo pela Universidade de Santiago de Compostela, Espanha. Graduação em Sociologia e Ciências Políticas pela UNED, Espanha. Professor Substituto de Estatística Experimental na Universidade Estadual do Maranhão, Campus de Imperatriz. E-mail: xoancarlossc@gmail.com

Livia de Freitas Navegantes Alves - Doutora pelo Centre International d’Études Supérieurs en Sciences Agronomiques, Montpellier SupAgro/Centre de Coopération Internationale en Recherche Agronomique pour Le Développement (CIRAD). Professora do Núcleo de Ciências Agrárias e Desenvolvimento Rural (NCADR) da Universidade Federal do Pará. E-mail: lnavegantes@ufpa.br
\end{abstract}

\section{Resumo}

As transformações técnicas dos sistemas de produção originam-se nas decisões dos agricultores. Porém ainda não são bem entendidos os elementos considerados pelos agricultores para decidir pela adesão às práticas agroecológicas. Neste trabalho, buscamos compreender as motivações dos agricultores familiares do Oeste maranhense para fazerem suas escolhas produtivas e tecnológicas, entendendo que fatores históricos foram decisivos para a diferenciação dos sistemas de produção, que fizeram com que alguns tivessem possibilidade de aderir às práticas agroecológicas e outros não. Através da análise retrospectiva, identificamos dois vetores de transformação que contribuem para que os agricultores deem respostas diferentes às mesmas influências. Variáveis externas, como disponibilidade de crédito, capacitação e agroindústrias; e decisões familiares, como beneficiar localmente a produção, introduzir gado ou culturas permanentes, influenciam no percurso dessas propriedades. Quando se criam grupos de interesse em agroecologia, cria-se um ambiente em que os camponeses sentem-se mais confiantes para testarem as práticas agroecológicas propostas.

\section{Palavras-chave}

Tipologia. Enfoque sistêmico. Campesinato. Retrospectiva. Trajetória.

\begin{abstract}
Technical transformations of production systems originate in the decisions of farmers. However, the elements considered by farmers to decide by adherence to agroecological practices are not yet well understood. In this work we try to understand the motivations of family farmers in Western Maranhão to make their productive and technological choices, understanding which historical factors were decisive in the differentiation of production systems, which caused some were unable to adhere to agroecological practices and others do not. Through retrospective analysis we identified two transformation vectors that contribute to farmers deem different answers to the same influences. External variables such as availability of credit, capacity building and agricultural industries; and family decisions, such as locally benefit the production, introducing cattle or permanent crops, influence the course of these farms. When groups of interest in agroecology are created an environment in which farmers feel more confident to test the proposed agro-ecological practices arise.
\end{abstract}

\section{Keywords}

Typology. Systems approach. Peasantry. Retrospective. Trajectory. 


\section{INTRODUÇÃO}

A agricultura camponesa, apesar de ser portadora de um acervo de conhecimentos acumulados tradicionalmente, está em constante transformação para adaptar-se à realidade socioeconômica e ambiental (TOLEDO; BARRERABASSOLS, 2008), buscando a sobrevivência da família e da unidade produtiva (CHAYANOV, 1981).

A agricultura familiar, conceito genérico que inclui o campesinato como uma forma particular "que se constitui enquanto um modo específico de produzir e de viver em sociedade" (WANDERLEY, 1996, p. 2), contrapõe-se, no Brasil, à grande propriedade, que se impõe como modelo dominante socialmente reconhecido.

No caso brasileiro, o campesinato enfrentou dificuldades para implantar um sistema produtivo diversificado, do tipo policultura-pecuária, como no campesinato europeu. Em parte devido à possibilidade de recorrer à caça e à pesca para suprir as necessidades de proteínas na alimentação familiar, em parte devido à dificuldade de garantia da posse da terra (VELHO, 2013). Isto implicou a impossibilidade de fertilização natural, compensada pela prática da agricultura migratória no sistema de corte e queima.

$\mathrm{Na}$ situação atual, em que não há mais a possibilidade de migrar para uma nova fronteira agrícola, na constante busca por autonomia do camponês "a diversificação pode constituir um meio para diminuir o nível de externalização do processo produtivo, garantindo maior autonomia e controle sobre o processo de reprodução social” (NIEDERLE e JUNIOR, 2009, p. 81). Em outros casos, o modelo da grande propriedade pecuária, a estabilidade comercial e o menor risco favoreceram o surgimento de um tipo de agricultor familiar especializado na criação de bovinos. As situações intermédias, inclusive a permanência nos sistemas tradicionais de corte e queima ou do extrativismo, dão lugar a uma gama de tipos de sistemas produtivos atuais.

As progressivas transformações técnicas dos sistemas de produção são originadas pelas decisões dos agricultores que, por sua vez, são tomadas com base em uma série de critérios. Vários pesquisadores têm se debruçado no estudo dos fatores e fenômenos que interferem na adoção ou adaptação destas mudanças técnicas (BUNCH, 1999; COCHRAN e BONNELL, 2006; CALVI, 2009). Mas ainda não são bem entendidos os elementos considerados pelos agricultores para tomar sua decisão quanto à adesão a práticas agroecológicas que têm sido amplamente difundidas em todo o Brasil, impulsionadas pelo movimento agroecológico. 
Neste trabalho, buscamos entender que fatores históricos foram decisivos para a diferenciação dos sistemas de produção e que fizeram com que alguns agricultores tiveram possibilidade de aderir às práticas agroecológicas, e outros não, e a relevância dos aspectos históricos, intra e extraestabelecimento familiar, na adoção de práticas agroecológicas. Para tanto, relacionamos as escolhas atuais com as opções feitas no passado e com a influência das variáveis socioeconômicas mais gerais.

Esta compreensão pode contribuir para melhorar a abordagem feita pelos agentes de intervenção externa e o desenho de políticas de desenvolvimento rural, que frequentemente convergem para a fortificação da agricultura familiar de mercado, privilegiando a elevação da renda (ROY, 2002), mas esquecendo a lógica interna e os constrangimentos históricos da economia familiar camponesa.

\section{METODOLOGIA}

Partindo de um enquadramento mais global das circunstâncias históricas regionais, aproximamo-nos progressivamente ao nível microssocial, familiar, mas considerando as influências dos níveis comunitário e regional. Esta aproximação progressiva ao objeto de estudo revestiu-se de uma importância maior porque faltam estudos prévios que abordem estes aspectos na escala regional, e ainda mais nas comunidades pesquisadas: Vila La Bote, no município de Buriticupu; Nova Conquista, em Açailândia; e Coquelândia, em Imperatriz; todas situadas na mesorregião Oeste maranhense e no bioma amazônico.

O trabalho de campo consistiu na coleta de dados secundários e primários, através das metodologias descritas abaixo e da nossa compreensão pessoal, elaborada através da convivência no dia a dia com os grupos camponeses pesquisados, e com a nossa experiência prévia na região, de mais de dez anos.

Como primeira aproximação na compreensão da dinâmica agrária regional, realizamos entrevistas históricas, com informantes-chave. A combinação de fontes secundárias com as entrevistas históricas permitiu detectar os fatos mais relevantes ocorridos historicamente no nível regional, que influenciam as escolhas produtivas dos sujeitos da pesquisa e a configuração atual dos seus sistemas de produção.

Em um segundo momento, identificamos os principais tipos de sistemas produtivos existentes entre os sujeitos estudados, a caracterização destes e atribuímos os casos significativos a cada tipo.

$\mathrm{Na}$ terceira fase da pesquisa, buscamos compreender a coerência das transformações que explicam a atual configuração dos sistemas produtivos. Para tanto, realizamos entrevistas retrospectivas com 12 camponeses, incluindo 
todos os tipos de sistemas de produção identificados. Buscamos uma perspectiva histórica que nos permitisse entender que papel tiveram as influências externas e os fatores internos que determinaram a sua trajetória no tempo. Através desta análise, conseguimos entender as dificuldades na adoção das técnicas agroecológicas e as possibilidades da sua integração na lógica de transformação dos sistemas produtivos.

Para tanto, usamos o método da análise retrospectiva, que foi proposto por Moulin et al. (2008) e adaptado por Navegantes-Alves et al. (2012), tendo, então, sido usado pela primeira vez no Brasil. O objetivo do uso desse método foi caracterizar as mudanças e dinâmicas dos sistemas de produção. A partir de uma entrevista retrospectiva, levantamos os fatos históricos acontecidos no estabelecimento, que relacionamos com eventos do meio externo identificados nas entrevistas históricas e cuja importância para o estabelecimento em estudo foi confirmada pelo entrevistado. Principal atenção foi dispensada à introdução ou ao abandono de práticas agrícolas no "devir" do estabelecimento. O objetivo era compreender as razões dos agricultores quanto às suas escolhas produtivas (MORIN et al., 2007). O interesse do método centra-se nas mudanças técnicas e nas práticas de gestão, portanto adequa-se aos objetivos formulados.

A análise retrospectiva foi aplicada a partir da tipologia, que se constitui em amostragem dirigida, qualitativa, que visa mostrar a diversidade (MICHELAT, 1987, p. 199), e não informar em que proporção cada tipo de estabelecimento representa o universo total da comunidade.

Procedeu-se de maneira que os próprios camponeses contassem a história do seu sistema produtivo, desde a implantação deste, obtendo basicamente dois tipos de informações: fatos e representações sobre sua história, justificando as mudanças de práticas em função dos elementos que o camponês julga estar entre os fatores de suas decisões. Apesar de os dados quantitativos informados e a cronologia dos eventos serem declarativos, a repetição da entrevista com o mesmo agricultor, a triangulação com a observação participante por um período superior a três meses de convivência e a aplicação de alguns instrumentos do Diagnóstico Rural Participativo, permitiram fazer ajustes e verificações que asseguram a confiabilidade dos dados.

A periodização reflete uma escolha do pesquisador, mas se embasa em elementos objetivos, as mudanças de práticas apontadas pelo camponês. Esta periodização também se informa com as entrevistas históricas realizadas na fase inicial da pesquisa de campo.

A consideração de um período histórico amplo facilitou a compreensão das estratégias, assim como os interesses e projetos da família camponesa. 
Permitiu também descobrir a dinâmica do sistema de produção e os fatores que causam estagnação ou mudança no mesmo.

Esta metodologia permitiu a sistematização das informações levantadas através da construção de crônicas dos sistemas de produção, uma representação gráfica das transformações das unidades de produção e a modelização do processo de diferenciação dos tipos de sistemas de produção encontrados na região.

\section{RESULTADOS E DISCUSSÃO}

\subsection{NOVA CONQUISTA}

A agrovila Nova Conquista pertence ao Projeto de Assentamento Açaí, criado pelo INCRA em 1996 sobre uma área de mata amazônica, no município de Açailândia. Os assentados eram, em maioria, residentes da periferia de Imperatriz, chegados recentemente das áreas rurais de diversos municípios do Maranhão, e assim que chegaram à área começaram a produzir arroz (Oryza sativa). Inicialmente as colheitas foram fartas, devido à grande quantidade de biomassa, importante para os cultivos de corte e queima, pois da mata original somente haviam sido retiradas algumas madeiras mais nobres.

$\mathrm{Na}$ Figura 1, sintetizamos as transformações ocorridas nos sistemas de produção identificados em Nova Conquista, através da agregação das crônicas dos estabelecimentos analisados. Os grandes retângulos arredondados representam fases temporais correspondentes a coerências técnicas em que se percebe o predomínio de uma "norma técnica de base", um conjunto de ideias comuns ao grupo, que evolui lentamente devido à pressão coletiva e que pode sofrer mudanças provindas de fatores externos ou desvios de conduta internos (SABOURIN, 2002, p. 188). As setas na parte superior situam temporalmente estes fatores externos aos sistemas de produção e os retângulos menores representam fatores internos provocando mudanças técnicas. Cada tipo de sistema de produção pode estar presente desde o início, neste caso a criação do assentamento, ou aparecer em determinada época e perdurar, ou não, ao longo do tempo. 
Figura 1 - Quadro geral de análise das mudanças nos sistemas de produção de Nova Conquista.

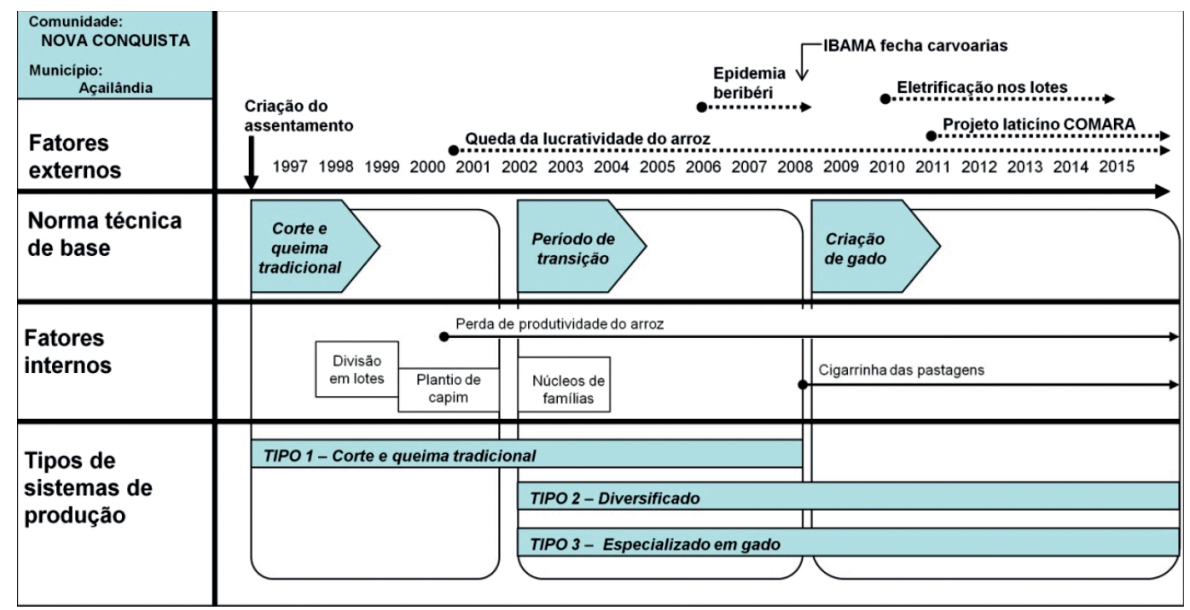

Fonte: Elaboração própria.

Quando cada assentado recebeu seu lote, deparou-se com a realidade da limitação da sua base de recursos. Com o tempo, as sucessivas roças e algumas queimadas que fugiram de controle foram dizimando as áreas adequadas para obterem altas produções de arroz. Como podemos ver na Figura 1, a partir de 2001, observa-se uma progressiva queda na produtividade do sistema de corte e queima tradicional. A crise agravou-se porque esta redução das colheitas foi acompanhada pela estagnação do preço do arroz, ao mesmo tempo em que a mão de obra se tornava cada vez mais cara e escassa, principalmente na intensiva fase da colheita manual. Esta escassez e carestia da mão de obra deve-se à urbanização acelerada do município, à atração de um mercado de trabalho local relativamente dinâmico se comparado ao conjunto do Maranhão e a fatores socioeconômicos mais gerais, como o aumento geral dos preços e o fortalecimento das políticas sociais de complementação de renda.

Outro fator que contribuiu para a diminuição da disponibilidade de áreas aptas ao cultivo de arroz no sistema de corte e queima foi a prática do plantio de capim ao fim do ciclo das culturas anuais. Em parte isto é devido ao costume, pois muitos camponeses eram obrigados a fazer isso em troca da cessão de áreas para plantio em fazendas pecuárias, nas suas regiões de origem. Isto é corroborado pelo fato de vários agricultores que não possuem gado e não fizeram nenhum investimento para estruturar o lote para a criação manterem até 50\% da propriedade com pastagem, como forma de "valorizar a terra" (CARVALHO et al., 2012). Por outro lado, vários camponeses leram rapidamente a dinâmica 
regional (na fala deles: "a região é leite") e buscaram se preparar para essa atividade. A decisão de plantar capim é de grande relevância para a dinâmica de transformação do sistema de produção, pois é de difícil reversão. Este fenômeno, conhecido como "dependência da trajetória" (HUBERT et al., 2013, p. 221), ganha importância em períodos de transição técnica, como o destacado na Figura 1 , de 2002 a 2008.

Os bancos e os escritórios locais de elaboração de projetos também influenciaram para que os camponeses embarcassem na atividade pecuária, atraídos pela viabilidade econômica do projeto, com relação a menores riscos e com a garantia do investimento que o próprio animal adquirido pode fornecer. Primeiramente fizeram-no de forma ideológica, ao incentivarem os agricultores familiares a dedicarem-se a esta atividade; depois de forma mais prática, ao negarem-se a elaborar ou financiar projetos para outras atividades. Assim, os primeiros projetos financiados para o assentamento, a partir de 2001, destinavamse à construção de cercas e açudes, a derrubadas mecanizadas para o plantio de capim e à aquisição de gado. Somente alguns núcleos de famílias, auspiciados pela militância do Movimento dos Trabalhadores Rurais Sem Terra - MST, saíram dessa lógica e financiaram outras atividades coletivas em grupos de cinco famílias (suinocultura, casa de farinha...). A falta de formação especializada e retorno financeiro da assistência técnica e a difícil realidade do mercado local, que só se comporta de forma estável para o gado de corte, levaram estes grupos dissidentes ao fracasso.

Outros camponeses foram progressivamente diversificando as atividades, incluindo novos plantios - de frutíferas e hortaliças principalmente -, e outros ainda aproveitaram o crescimento da bovinocultura de leite e o consequente excesso de soro no laticínio vizinho para reintroduzir a suinocultura.

Conforme se observa na Figura 1, nos últimos anos da década de 2000, a produção de arroz tornou-se praticamente inviável para a maioria dos assentados e os sistemas produtivos do tipo roça de corte e queima praticamente deixaram de existir em Nova Conquista. Além da equação econômica que aumentou os custos e diminuiu a receita, a produtividade continuava caindo. A situação ficou mais dramática ainda com o surgimento de um surto de beribéri na região, que causou várias mortes e cuja causa foi atribuída à falta de condições higiênicas de estocagem do arroz. A sucessão de fiscalizações por parte da Agência Estadual de Defesa Agropecuária - AGED, que chegou a fechar várias beneficiadoras de arroz na região, aliada à desconfiança dos consumidores urbanos por parte do arroz local, que derrubou ainda mais os preços, fez com que as usinas sumissem de Nova Conquista. Mas o que terminou de derrubar a hegemonia deste sistema 
de produção foi a chegada, a partir de 2008, de uma forte infestação de cigarrinha das pastagens (Hemiptera: Cercopidae), que foi depois acompanhada por uma doença fúngica no solo. Foram vários anos em que os mais teimosos tinham que replantar duas e até três vezes suas roças de arroz ou milho (Zea mays), apesar de que invariavelmente no final da colheita, quando existia, o prejuízo financeiro era certo.

Alguns moradores citam também o fechamento de uma carvoaria por parte do IBAMA como mais um fator que contribuiu para piorar as contas dos que praticam o sistema de corte e queima, pois a venda da madeira ajudava a aumentar as receitas, mesmo que de forma pouco significativa. Mesmo assim, a maioria disse apoiar o fim da produção de carvão no assentamento.

Dessa forma, progressivamente a atividade pecuária de leite foi ganhando espaços em Nova Conquista, até tornar-se a nova norma técnica de base, como podemos observar na Figura 1. Neste ponto, a militância do MST local aceitou finalmente esta tendência e buscou ativamente liderar o processo. Assim, resgatou-se um projeto antigo do MST da região tocantina de implantar um laticínio organizado através da Cooperativa Maranhense dos Assentados da Reforma Agrária - COMARA, vinculado ao movimento, e direcionou-se para Nova Conquista. Em 2014, este projeto foi aprovado pelo Banco Nacional de Desenvolvimento Econômico e Social - BNDES e está em fase de implantação.

Paralelamente, outros camponeses resistiram à introdução do gado ou ao seu predomínio nos sistemas de produção. Estes incluíram novas atividades, como a horticultura, as culturas permanentes, campos agrícolas, a suinocultura e a ovino-caprinocultura, constituindo um tipo de sistema de produção que denominamos "diversificado", como se observa na Figura 1. É um fato relevante que alguns agricultores deste tipo, notadamente aqueles mais influenciados pelo MST e cooperados da COMARA, com a iminência da chegada de um laticínio próprio ao assentamento, inseriram o gado no sistema de produção ou iniciaram a estruturação do lote para permitir a sua inserção. Estes afirmam não querer "perder o carro" do desenvolvimento que vislumbram nessa atividade, mas deixando claro que não abandonam as atividades que já vêm praticando.

\subsection{COQUELÂNDIA}

Coquelândia é uma comunidade formada por posseiros chegados a Imperatriz em 1958. Faz parte da chamada 'estrada do arroz', polo do município que se formou durante o auge desta cultura, nos anos 50 a 70 . Esta pujança, comum a outras regiões do Maranhão, tornou o estado o primeiro produtor 
de arroz do Brasil na década de 1960 (FRANKLIN, 2008). O acesso à terra era feito sem nenhum documento, o que favoreceu que os posseiros fossem paulatinamente empurrados para fora das áreas que ocuparam durante anos. Isto contribuiu para o crescimento do povoado Coquelândia e vários outros ao longo da 'estrada do arroz', aonde chegavam os camponeses expulsos dos 'centros’ próximos, localizados mais ao interior da mata (VELHO, 2013, p. 113). Os fazendeiros, às vezes mediante coação, outras vezes chegando ao uso da violência física, iam se apossando de cada vez mais vastas áreas. As matas iam se transformando em pastagens, frequentemente através da cessão de áreas para os camponeses plantarem suas culturas anuais em troca do pagamento de renda em espécie e a obrigação de plantar capim no final do ciclo. A abundância de babaçu (Orbignya spp) também contribuiu para que, mesmo sem a posse da terra, as famílias obtivessem seus meios de subsistência dos recursos naturais a seu redor e pudessem permanecer na forma de vida camponesa, principalmente produzindo azeite de babaçu.

O predomínio dos sistemas de produção de roça de corte e queima, convivendo com os baseados no extrativismo, no primeiro período da comunidade pode ser visualizado na Figura 2.

Figura 2 - Quadro geral de análise das mudanças nos sistemas de produção de Coquelândia.

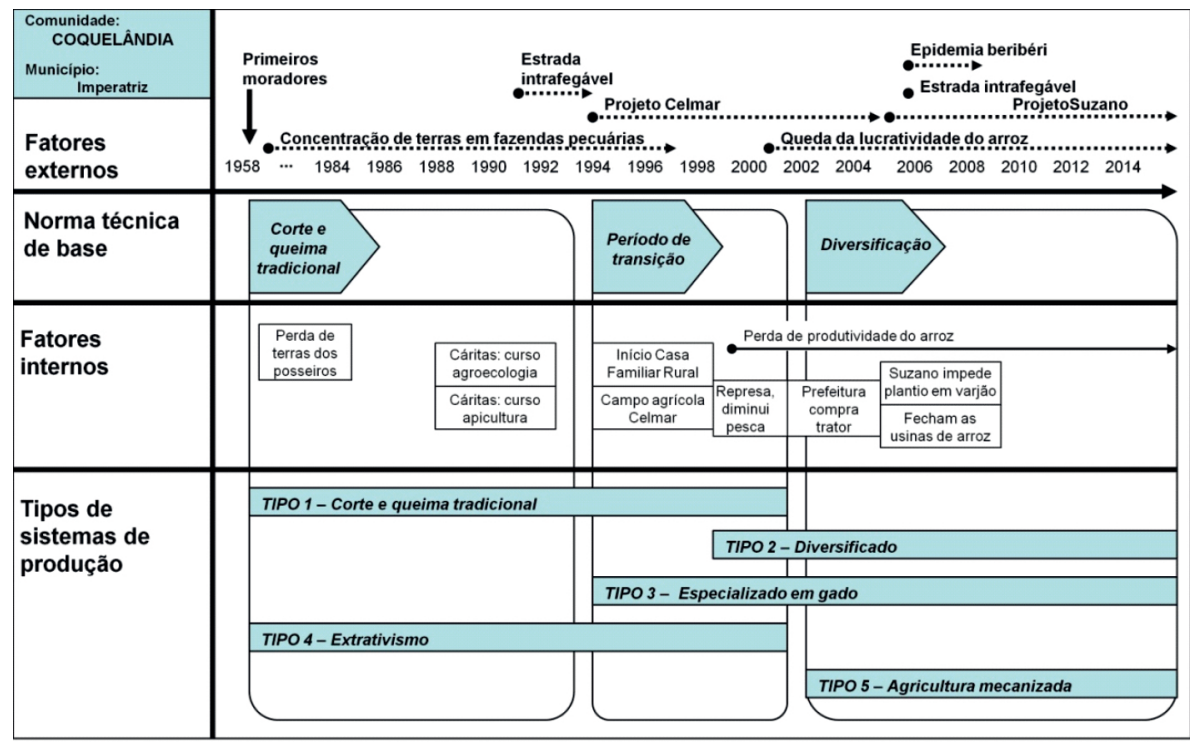

Fonte: elaboração própria. 
Porém o avanço da pecuária e a implantação de um grande projeto de plantio de eucalipto (Eucalyptus spp) do consórcio CELMAR, durante a década de 1990, fez com que se tornasse cada vez menor a disponibilidade de mata para a prática de corte e queima tradicional e a coleta de babaçu. Como se observa na Figura 2, esses tipos de produção, embora não tenham desaparecido totalmente, entraram em declínio.

Alguns camponeses que possuíam terra foram introduzindo a criação de gado, que foi progressivamente ganhando espaço nas suas propriedades até se especializarem nessa atividade. Outros iniciaram um processo de diversificação produtiva, introduzindo novas atividades, como a apicultura ou a horticultura.

A partir de 1994 (conforme Figura 2), o consórcio CELMAR começou a cessão de pequenas áreas mecanizadas comunitárias para as associações dos povoados, permitindo o plantio de culturas anuais em 1 ha para cada sócio. A partir da década de 2000, com a aquisição por parte da prefeitura municipal de Imperatriz de um trator para servir aos pequenos produtores, alguns camponeses sem terra começaram a viabilizar os próprios quintais (em média 0,3 ha) para o plantio de culturas anuais de subsistência. Inaugura-se, então, em Coquelândia o sistema de produção 'agricultura mecanizada'. Mas há que entender que neste sistema de produção somente o preparo inicial do terreno é feito com grade e trator, e todas as demais operações são manuais. Usam-se inseticidas, herbicidas e adubo químico, de acordo com as recomendações da empresa.

Como se observa na figura 2, a aparição desse novo tipo de sistema de produção, unida à consolidação dos tipos diversificado e especializado em criação de gado que vinham se alicerçando desde o período de transição de 1994 a 2002, abre uma nova coerência técnica, que denominamos diversificação, pela convivência de três tipos principais de sistemas de produção. Os sistemas de corte e queima e do extrativismo continuam existindo, embora em proporção bem menor, possibilitados no primeiro caso pelas aposentadorias rurais e no segundo pelas políticas sociais de distribuição de renda, sem as quais se tornariam inviáveis.

\subsection{VILA LA BOTE}

A Vila La Bote, também conhecida como comunidade São José, com 30 famílias, faz parte do Projeto de Assentamento Lago Azul, implantado pelo INCRA em 1990 no município de Buriticuou-MA para regularizar uma ocupação feita por agricultores sem terra em 1989.

Após um período inicial em que as principais atividades eram a produção de arroz, a extração de madeira e a pesca no Pindaré, rio que margeia o 
assentamento, sucedeu-se uma etapa de intensa substituição dos primeiros assentados por novos moradores que, com o consenso da comunidade, ocupavam os lotes dos desistentes. Desta forma, a chegada de um grande grupo familiar camponês (pai mais oito filhos adultos), que posteriormente foi tecendo laços matrimoniais que chegam a quase toda a vila, confere a esta comunidade uma característica diferencial que a torna de alguma forma fechada sobre si mesma. A entrada de novos moradores deve ser aprovada pelo coletivo, que zela para evitar a intrusão de quem não é "lavrador". Contribuiu para esse relativo isolamento a condição de intrafegabilidade da estrada, sobretudo nos anos da consolidação do assentamento, como indicado na Figura 3.

Figura 3 - Quadro geral de análise das mudanças nos sistemas de produção de Vila La Bote.

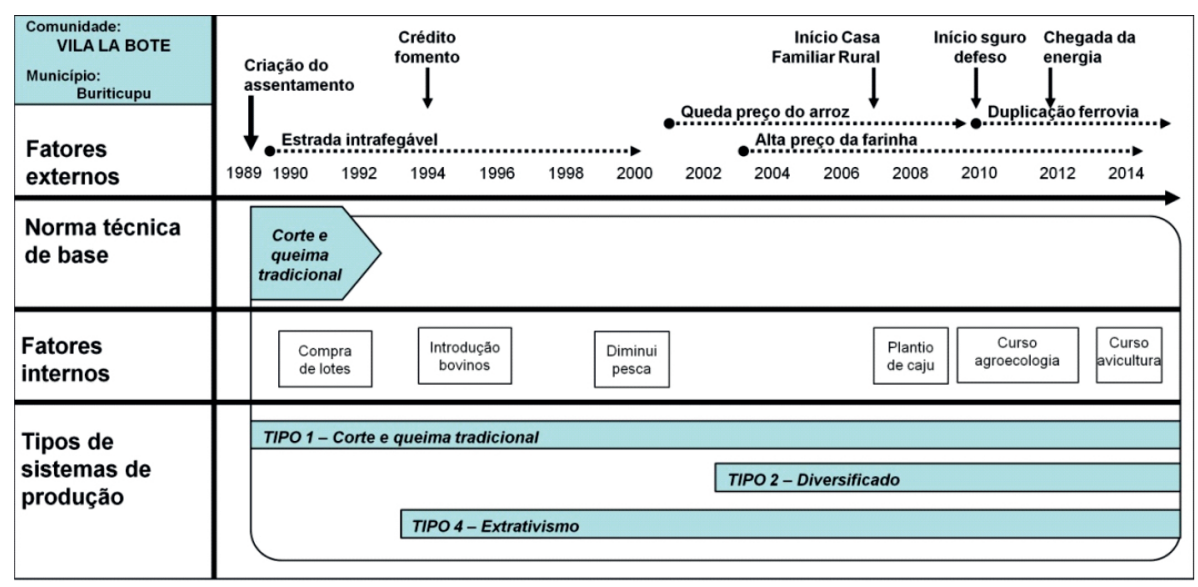

Fonte: elaboração própria.

Essa dinâmica interna favoreceu a existência de uma norma técnica de base forte e uma sólida homogeneidade dos sistemas de produção e das práticas agrícolas. No início, todos se dedicavam à agricultura tradicional através do sistema de corte e queima. As atividades extrativistas (pesca e caça principalmente) eram complementares e visavam basicamente prover uma fonte de proteína para a alimentação familiar. Com o tempo, o extrativismo foi reforçado, chegando a constituir um tipo de sistema de produção, conforme Figura 3, devido a dois fatores importantes. Por um lado, a chegada de novos moradores sem terra, os chamados "encostados", que, embora conseguissem fazer seus plantios de culturas anuais em áreas cedidas nos lotes dos assentados ou em áreas comunitárias ("patrimônio" da vila), tinham a caça e a pesca como duas atividades básicas para a subsistência e a comercialização. Por outra parte, junto com a expansão das 
áreas desmatadas para a prática da agricultura tradicional, expandia-se a palmeira babaçu, inicialmente restrita a uma pequena área de baixada, o que favoreceu a aparição de uma nova atividade extrativista que, porém, nunca atingiu na Vila La Bote a importância que tem em outras regiões do estado.

A partir de 1994, foram realizados projetos, através de financiamentos públicos, para a introdução da bovinocultura no assentamento. Apesar de ter sido ofertado um curso de criação de gado (três dias de duração), esta nova produção não teve sucesso. Parte dos recursos não chegou às mãos dos contratantes e os que chegaram a iniciar a atividade permaneceram pouco tempo nela, vendendo o gado e até mesmo parte dos materiais (arame e sementes). Este fracasso é atribuído pelos assentados à falta de estrutura dos lotes (cercas e, sobretudo, falta de água), à pouca habilidade no manejo e à total inexistência de assistência técnica. Como consequência, a maioria dos assentados continuou dedicandose à agricultura tradicional. Mas outros migraram para a sede do município ou para grandes cidades e houve ainda quem iniciara uma sucessão de migrações e retornos, vivendo principalmente do extrativismo e venda de mão de obra quando no assentamento. $\mathrm{O}$ certo é que ninguém continuou na atividade pecuária.

Nos primeiros anos da década de 2000, uma combinação de preços estagnados do arroz e alta no preço da farinha, como ressaltado na Figura 3, contribuiu para que a cultura da mandioca (Manihot esculenta) ganhasse espaço nas roças da Vila La Bote, mas sem grandes alterações quanto ao sistema de produção. Agregou-se, porém, uma atividade de processamento local, a produção da farinha, que propiciou um maior aproveitamento da mão de obra familiar e uma pequena capitalização dos camponeses, embora ainda precária. Esta melhoria da situação econômica das famílias permitiu um avanço na qualidade de vida, facilmente perceptível, por exemplo, na quantidade de motocicletas adquiridas. Em alguns casos essa capitalização trouxe a possibilidade de investir novamente na aquisição de gado, mesmo que em nenhum caso essa atividade viesse a substituir a predominância da agricultura de corte e queima no sistema produtivo, mas a torná-lo mais diversificado, servindo como uma poupança viva e uma segunda fonte de renda.

Essa senda da diversificação progressiva do lote viu-se intensificada na segunda parte da década de 2000 e início da de 2010, primeiro de forma espontânea com a introdução do caju (Anacardium occidentale), conforme Figura 3, e posteriormente incentivada pela atividade da rede Justiça nos Trilhos, que promoveu um curso de agroecologia na comunidade. Mais recentemente, uma maior presença da secretaria municipal de agricultura, incentivando a venda da produção familiar para os programas de aquisições governamentais, aponta 
para um aprofundamento dessa tendência à diversificação, incluindo atividades como horticultura e avicultura.

Porém, na nossa avaliação, o sistema de produção de corte e queima continua imperando, estruturando uma norma técnica de base forte e homogênea, revigorada pelo sucesso da transformação local da farinha. Por esse motivo, como mostrado na Figura 3, consideramos para a Vila La Bote uma única fase ou coerência técnica que permanece até a atualidade.

\subsection{AS TRANSFORMAÇÕES DOS SISTEMAS DE PRODUÇÃO}

Nas entrevistas retrospectivas realizadas nas comunidades estudadas, percebemos dois vetores que guiam as transformações dos sistemas de produção, que correspondem às duas principais estratégias seguidas para o planejamento da propriedade, relacionadas com os ideais e objetivos do agricultor. O primeiro consiste no "ideal da fartura", vinculado ao modo de vida tradicional camponês e caracterizado por uma propriedade autossuficiente, diversificada e com fartura de produtos alimentares. O segundo consiste no "ideal do fazendeiro", que se espelha no status do grande pecuarista e que se caracteriza pelo modelo da fazenda pecuária: uma propriedade "gramada", de tamanho crescente e cujo sucesso se mede pela quantidade de cabeças de gado que possui.

Esses dois vetores de transformação contribuem para que os agricultores familiares deem respostas diferentes às mesmas influências provenientes do meio socioambiental. Esta sucessão de adaptações diferentes, guiadas pelos dois vetores descritos anteriormente, conduzem à diferenciação dos sistemas produtivos, partindo dos tipos originais (corte e queima tradicional e extrativismo), até os atuais (diversificado, agricultura mecanizada e criador de gado). Estas trajetórias adaptativas podem ser observadas de forma sintética na figura 4.

Quando o agricultor percebe que está acontecendo um aumento geral de preços no mercado, provocando uma alta simultânea de suas receitas e custos de produção, sente-se impulsionado a realizar mudanças técnicas que permitam um ganho de lucratividade, apropriando-se de uma maior fatia do aumento de receitas ou reduzindo seus custos.

Nas nossas entrevistas, identificamos duas estratégias principais para conseguir esta meta. A primeira é o processamento local da produção, como se observa na Figura 4, nomeadamente através da produção de farinha de mandioca. Esta estratégia permite certa capitalização das famílias, embora ainda precária, através da venda de um produto com maior valor agregado. Isto se consegue com um investimento relativamente modesto, geralmente coletivo, e 
uma intensificação do uso de mão de obra na estação seca, época mais ociosa do calendário de trabalho anual. Também tem reflexo direto nas mudanças no sistema de produção (maior área destinada à mandioca) e nas práticas agrícolas, entre elas as agroecológicas (por esta cultura ter um ciclo de cultivo mais longo, por favorecer o consórcio com outras espécies e por ser pouco atingida por problemas fitossanitários).

Figura 4 - Modelo simplificado do processo de diferenciação dos tipos de Sistemas de Produção na agricultura camponesa.
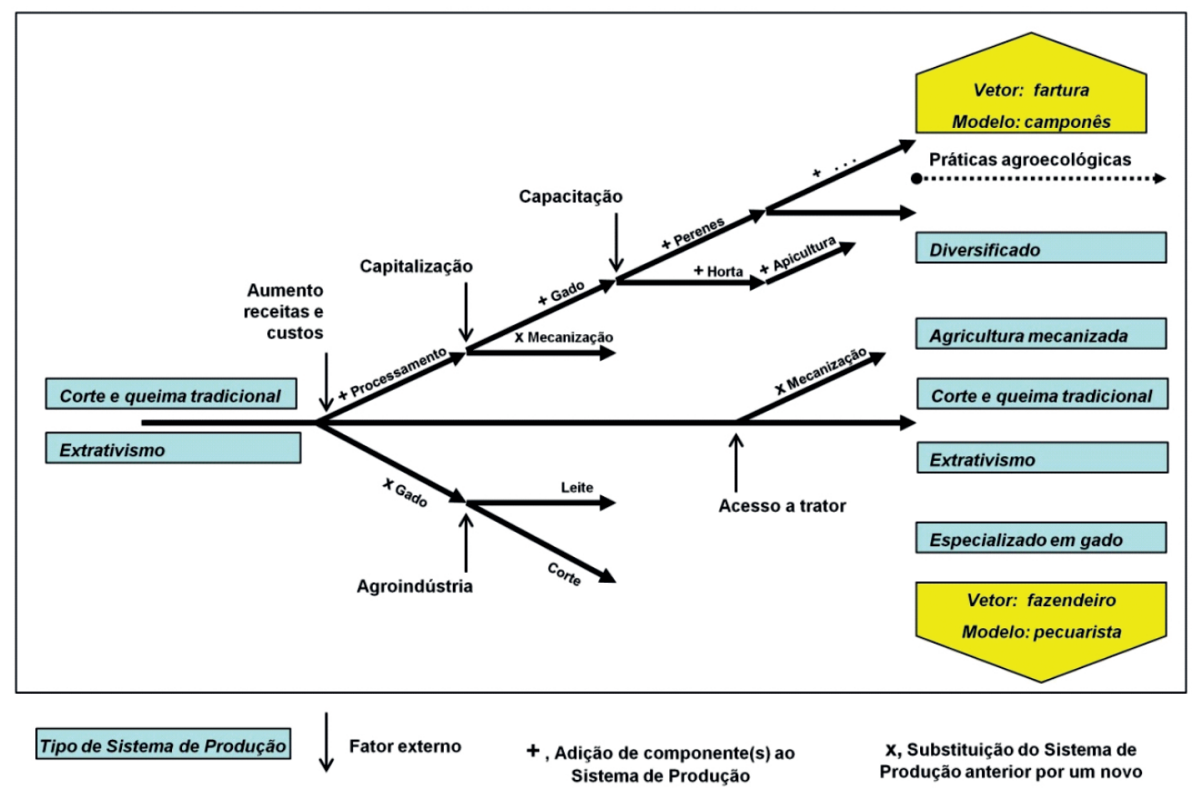

X, Substituição do Sistema de Sistema de Produção

Fonte: elaboração própria.

Quando a capitalização provém do processamento local, além de melhorar a qualidade de vida da família, usa-se o reinvestimento normalmente na diversificação do sistema de produção, especialmente quando há ofertas de capacitação, adicionando novas atividades (como indicado pelo signo "+" na Figura 4). Estas adições geram complementaridade, diminuem os riscos e contribuem para um melhor aproveitamento da mão de obra familiar. Alguns componentes frequentemente adicionados são as culturas perenes, a horticultura e a apicultura, embora qualquer nova atividade possa ser acrescentada, dependendo das preferências e habilidades do agricultor, como representado por "..." na Figura 4. É importante notar aqui que uma destas atividades novas pode ser a criação de gado, mas neste caso a inclusão deste componente tende a diversificar o sistema, não à homogeneização por substituição dos componentes 
preexistentes. Nestes casos, a inclusão do gado permite uma maior integração das atividades por meio do fechamento de ciclos de nutrientes, um melhor aproveitamento da mão de obra e uma maior capitalização da família, que pode ser reinvestida na continuação do processo de diversificação.

O sucesso na gestão de um sistema de produção diversificado, portanto mais complexo, sugere uma maior compreensão dos limites e possibilidades dos recursos disponíveis na propriedade e um conhecimento rudimentar, mas prático, dos princípios agroecológicos. As experiências positivas em produções até então desconhecidas também sugere certa predisposição a assumir riscos, mesmo que limitados, o que favorece que queiram testar novas práticas agroecológicas (como indicado na linha tracejada da Figura 4). Este tipo de agricultorestorna-se mais receptivo às propostas de agroecologia, que, além de oferecer ferramentas para melhorar seus sistemas de produção, proporciona um discurso condizente com o ideal da fartura camponesa.

A segunda estratégia identificada é a especialização em bovinocultura extensiva, com reduzido emprego de mão de obra e, portanto, reduzindo os custos de produção. Neste caso, quando a criação de gado permite certa capitalização, esta reverte-se em melhorar a qualidade de vida da família e reinveste-se no aprofundamento e expansão do novo sistema de produção. A presença nas proximidades de uma agroindústria de laticínios, ou uma rota de coleta estável, provoca uma diferenciação entre os que optam por esta estratégia, pois muitos escolhem produzir leite, como indicado na Figura 4, podendo combinar a orientação de corte e leite.

Uma terceira via, identificada com menor frequência e praticamente limitada a uma das três comunidades pesquisadas, é a da mecanização. O desencadeante desta estratégia pode ter duas vertentes, como observado na Figura 4. No primeiro caso, agricultores que possuem terra e conseguiram uma incipiente capitalização, por exemplo, mediante a produção de farinha de mandioca, decidem pagar a terceiros pelo preparo mecanizado do solo, como forma de intensificar seus sistemas de produção baseados nas culturas anuais. No segundo caso, agricultores sem terra conseguem a cessão de pequenas áreas e o serviço mecanizado de preparo do solo das empresas que plantam eucalipto. Ou seja, agricultores que plantavam roças de corte e queima em áreas cedidas por fazendeiros, mas que possuem quintais de tamanho suficiente, conseguem que a prefeitura municipal realize a mecanização destes. Em ambos os casos, o sistema de produção anterior é substituído (como indicado pelo signo "X" na Figura 4) por outro baseado em culturas anuais em que somente as operações de preparo do solo são feitas de forma mecanizada, permanecendo mais ou menos inalteradas as restantes operações de manutenção dos plantios e colheita. No 
primeiro caso, há margem para que a transformação do sistema de produção continue, podendo ser agregados novos componentes, numa trajetória semelhante à dos diversificados. No segundo caso, este desenvolvimento é limitado pela não disponibilidade terra.

A figura 5 representa uma trajetória típica de transformação da propriedade de um sistema de produção do tipo diversificado.

Figura 5 - Trajetória de diversificação de um lote padrão do tipo diversificado.

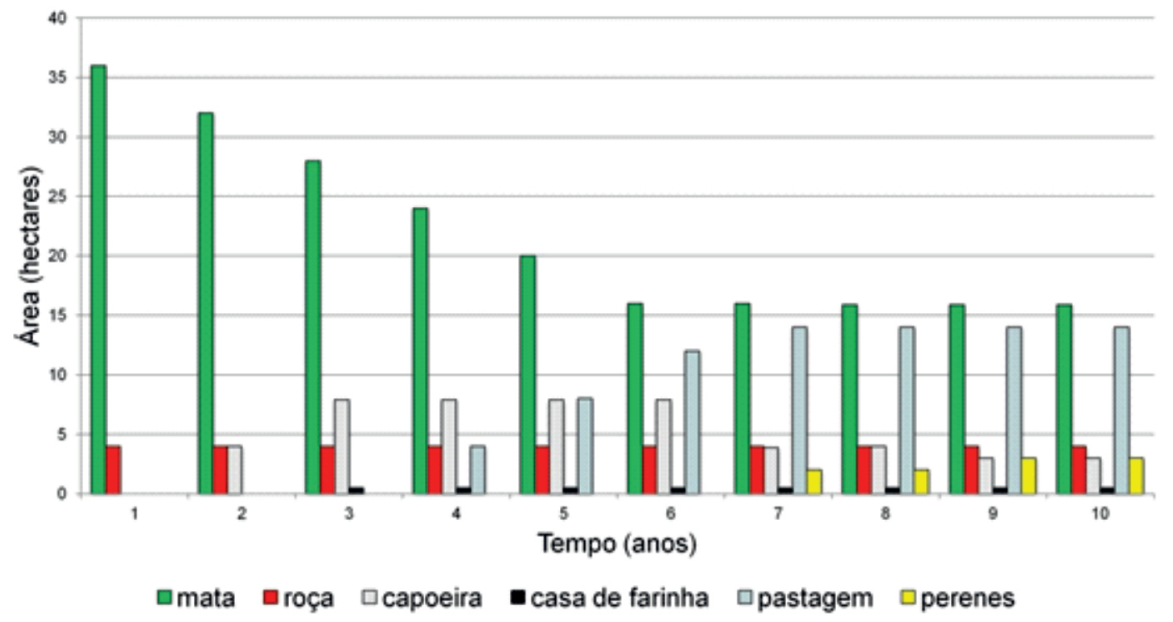

Esse tipo de agricultores, quando tem a possibilidade de receber alguma capacitação ou de participar de grupos acompanhados por agentes externos, apresenta maior tendência a aprofundar a diversificação dos seus sistemas de produção, acrescentando novas atividades produtivas, como mostrado nas Figuras 4 e 5.

Como se observa na Figura 5, a introdução do gado como componente diversificador acontece quando o agricultor percebe que os recursos do lote tendem ao esgotamento. Assim, a bovinocultura de leite tem grande importância na agricultura familiar, cumprindo seu papel de absorver mão de obra, agregar valor à propriedade, diversificar o sistema e permitir certa intensificação que torna a atividade mais sustentável social e ambientalmente (CARVALHO et al., 2012).

Quando a agroecologia é introduzida como tema de reflexão e análise a partir de grupos de debate e existe um efetivo acompanhamento técnico dos agentes externos, cria-se um ambiente em que os camponeses sentem-se mais confiantes a testar algumas práticas agroecológicas propostas. Foi somente em situações como esta que identificamos a introdução das roças sem fogo, dos inseticidas naturais, dos sistemas agroflorestais e do uso de composto orgânico nas comunidades estudadas. 


\section{CONCLUSÕES}

Não só os atuais fatores internos e externos condicionam a configuração do sistema de produção, mas também os fatores internos e externos que incidiram no passado contribuem para explicar o presente. Assim, comunidades que sofreram durante décadas com estradas em péssimas condições de trafegabilidade e que não tinham acesso à assistência técnica ou a capacitações tendem a buscar atividades que tenham menos dependência de uma comercialização frequente e de conhecimentos especializados, como a produção de gado de corte. Mesmo quando o problema da estrada e da assistência técnica é resolvido, algumas opções técnicas não estão mais disponíveis. Assim, por exemplo, quem transformou toda sua propriedade em pastagem provavelmente só poderá escolher entre criar gado de corte ou de leite.

Outros fatores históricos estão diretamente relacionados ao mercado, como a perda de competitividade da produção de arroz nos sistemas tradicionais devido às altas no preço da mão de obra. Neste caso, incide também o esgotamento progressivo da fertilidade do solo e a maior incidência de problemas fitossanitários, ambos relacionados com a diminuição das áreas de mata, o que leva a safras mais fracas.

Questões sociais, como a organização coletiva, na forma de cooperativas que criam agroindústrias, ou de associações comunitárias que estabelecem parcerias com grandes empresas ou com as prefeituras, ou ainda que constituem grupos de base do movimento social agroecológico, também contribuem para dar formas diferentes às trajetórias dos sistemas de produção locais ao longo do tempo, com repercussão direta nas diferentes possibilidades de adoção de práticas agroecológicas.

A presença do gado no sistema de produção, apesar de historicamente ter sido um elemento problemático e contraditório, em ocasiões contestadas pelos movimentos sociais do campo, atualmente pode supor para o camponês um elemento de estabilidade financeira que lhe permita uma margem de erro para aventurar-se a experimentar as práticas agroecológicas.

Dessa forma, apesar de os agentes que promovem a agroecologia na região de estudo terem centrado seus esforços na produção vegetal, abre-se a possibilidade de construção de uma agroecologia de sucesso no Oeste maranhense a partir da produção de leite orgânico ou baseado nos princípios agroecológicos. Isto permite estabelecer um fio condutor entre os diferentes tipos de sistemas de produção identificados na região, estabelecendo um diálogo com a nova norma técnica de base que está se consolidando no território e acompanhando a dinâmica regional. 
O fortalecimento das estratégias de processamento local da produção, de forma familiar ou comunitária, e a capacitação em atividades de pequena escala que já mostraram bons resultados no Oeste maranhense (como a horticultura, apicultura, piscicultura e algumas culturas perenes), apontam-se também como um esquema promissor para a promoção das práticas agroecológicas e da sustentabilidade do modo de vida camponês.

Neste trabalho, a perspectiva histórica adotada através da análise retrospectiva, a construção de crônicas dos sistemas de produção e a elaboração de modelos de transformação dos sistemas de produção, possibilitou perceber que o passado continua influenciando no leque de possibilidades atuais dos camponeses da região. Também nos permite compreender como os ideais perseguidos por estes sujeitos, unidos a uma análise detalhada da conjuntura, incidem fortemente no processo de tomada de decisões dos camponeses, fazendo com que se deem respostas diferentes às mesmas influências do meio.

\section{REFERÊNCIAS}

ALMEIDA, M. CUNHA, M. C. da, ELOY, L., EMPERAIRE, L. KATZ, E., SIMONI, J., RIZZI, R., SANTILLI, J., VELTHEM, L. V. L’indication géographique, un instrument de pérennisation des productions localisées en Amazonie? Le cas de la farine de manioc de Cruzeiro do Sul (Acre, Brésil).Belém, Novos Cadernos NAEA. NAEA/UFPA. Vol. 12, n. 1. p. 93-108, jan-jun 2009.

BUNCH, Roland. Reasons for non-adoption of soil conservation technologies and how to overcome them. Mountain Research and Development, 1999, p. 213-219.

CALVI, M.F. Fatores de adoção de sistemas agroflorestais por agricultores familiares do município de Medicilândia, Pará. Dissertação (Mestrado em Agriculturas Familiares e Desenvolvimento Sustentável) - Universidade Federal do Pará, 2009.

CARVALHO, S. A. D.; TOURRAND, J. F.; POCCARD-CHAPUIS, R. Atividade leiteira: um desafio para a consolidação da agricultura familiar na região da transamazônica, no Pará. Cadernos de Ciência \& Tecnologia, v. 29, n. 1, p. 269-290, 2012.

CHAYANOV, A. Sobre a teoria dos sistemas econômicos não capitalistas. In: SILVA, J. G. D. S., V. (Ed.). Questão agrária: Weber, Engels, Lenin, Kautsky, Chayanov, Stalin. São Paulo: Brasiliense, 1981 [1924]. p.133-164.

COCHRAN, J. B.; BONNELL, R. Patterns of sustainable agriculture adoption/ non-adoption in Panama. Journal of Sustainable Agriculture, v. 27, n. 3, 2006, p. 147-162. 
FRANKLIN, A. Apontamentos e fontes para a história econômica de Imperatriz. Ética, 2008.

HUBERT, B. et al. Conclusion: en route... but which way? In: COUDEL, E. (Org.) Renewing innovation systems in agriculture and food: how to go towards more sustainability? Wageningen Academic Pub, 2013.

MICHELAT, G. Sobre a utilização da entrevista não-diretiva em sociologia. In: THIOLLENT, M. (Ed.). Crítica metodológica, investigação social e enquete operária, v.5, 1987. p.191-211.

MORIN, G. et al. Dynamiques des unités de production laitière dans le bassin d'approvisionnement de la ville de Ségou au Mali. Revue d'élevage et de médecine vétérinaire des pays tropicaux, 2007, v. 60, n. 1-4.

MOULIN, C. H. et al. Comprendre et analyser les changements d'organisation et de conduite de l'élevage dans un ensemble d'exploitations: propositions méthodologiques. In: DEDIEU, B. et al. (Org.). L'élevage en mouvement: flexibilité et adaptation des exploitations d'herbivores. Paris: Quae, 2008. p. 181-196.

NAVEGANTES-ALVES, L. et al. Transformações nas práticas de criação de bovinos mediante a evolução da fronteira agrária no sudeste do Pará. Cadernos de Ciência \& Tecnologia, v. 29, n. 1, 2012, p. 243-268.

NIEDERLE, P. A.; JUNIOR, V. J. W. A agroindústria familiar na região Missões: construção de autonomia e diversificação dos meios de vida. Redes, v. 14, n. 3, 2009, p. $75-102$.

ROY, G. A agricultura familiar nas frentes de colonização da Transamazônica: ensaio crítico sobre as abordagens agroeconômicas. Agricultura Familiar: Pesquisa, Formação e Desenvolvimento, Belém, v. 1, n. 3, 2002, p. 81-107.

SABOURIN, E. Manejo da inovação na agricultura familiar do Agreste da Paraíba: o sistema local de conhecimento. In: SILVEIRA, L.;PETERSEN, P.; SABOURIN, E. (Ed.) Agricultura familiar no semi-árido: avanços a partir do agreste da Paraíba. Rio de Janeiro: AS-PTA, 2002.

TOLEDO, V. M.; BARRERA-BASSOLS, N. La memoria biocultural. La importancia ecológica de las sabidurías tradicionales. Barcelona: Icaria, 2008.

VELHO, O. G. Frentes de expansão e estrutura agrária: estudo do processo de penetração numa área da Transamazônica. 3. ed. Manaus: UEA Edições, 2013 [1972].

WANDERLEY, M. D. N. B. Raízes históricas do campesinato brasileiro. Anais... XX Encontro Anual da ANPOCS. Gt 17. Processos Sociais Agrários. Outubro 1996, Caxambu, MG. 
